\title{
On Presentist Perdurantism ${ }^{1}$
}

\author{
Jiri Benovksy \\ University of Fribourg
}

\begin{abstract}
The combination of perdurantism and presentism has an alleged nice advantage: it seems to avoid the 'no-change objection' to four-dimensionalism (non-presentist perdurantism). The purpose of this paper is, firstly, to argue that this is not true, and that the 'no-change objection' applies to presentist perdurantism with as much strength as it applies to four-dimensionalism, and secondly, that there are additional difficulties with this view, mainly due to the claim that wholes can have parts that don't exist.
\end{abstract}

Keywords: presentism, eternalism, perdurantism, four-dimensionalism, persistence, time, change

$\$ 1$ The perdurantist's central claim is that ordinary material objects are aggregates of temporal parts and that they persist (perdure) from one time to another by having different temporal parts at different times. These temporal parts are 'time-bound', that is, they don't exist at more than one time (or time-span, if they are temporally extended). Aggregates of temporal parts (ordinary material objects, people, ...) of course can and do exist at more than one time, but only by having numerically distinct temporal parts at different times. ${ }^{2}$ Perdurantism can be combined with two views about time: eternalism and presentism.

Eternalism is the doctrine about time which takes all times to exist, and to be ontologically on a par - there is no ontological difference between past, present and future times. As Ted Sider puts it: "Just as distant places are no less real for being spatially distant, distant times are no less real for being temporally distant" (Sider 2001, p. 11). Thus, past and future objects exist, just as present objects do. The present time and presently existing objects have no ontological privilege, and "now" is an indexical term just like "here".

1 For very helpful comments on earlier versions of this paper, I would like to thank Fabrice Correia, Gianfranco Soldati, David Stauffer, as well as two anonymous referees of Sats.

2 This is the perdurantist 'worm view'. I will discuss the 'stage view' in $\S 3$. 
Contrary to eternalism, presentism claims that only presently existing objects are real - "to exist", then, amounts to "to exist now". Typically, presentists are also 'serious tensers' drawing an important distinction between saying that past objects once existed and future objects will exist but only current objects exist. One could think, at a first glance, that presentism, thus formulated, is a non-starter - for how is one to understand the presentist's central claim "The only things that exist are those that exist at present"? It seems there are two possibilities: either the first occurrence of "exist" in this claim is tensed or it is not. If it is, then it seems that presentism is an uninteresting truth ("The only things that exist now are those that exist at present"), and if it is not - that is, if "exist" is to be taken as a tenseless form of the verb meaning something like "existed, exist, or will exist" - then presentism seems to be obviously false. But even if it is perhaps not easy to formulate the presentist view in a non-controversial way, it certainly is not a 'non-starter' - what the view wants to claim is simply that there are fewer objects than those recognized by the eternalist. Thus, presentism is a thesis about what there is, as for instance Zimmerman puts it: "[T]here is only one largest class of all real things, and this class contains nothing that lies in the past or future. Presentism is, in fact, a thesis about the range of things to which one should be ontologically committed" (Zimmerman 1998, p. 210).

The combination of perdurantism and eternalism is traditionally called "four-dimensionalism", and the combination of perdurantism and presentism can simply be called "presentist perdurantism". It is the purpose of this paper to explore some aspects of this latter view, while comparing it to the fourdimensionalist one, and to argue that it falls prey to serious difficulties.

$\$ 2$ Let us consider the presentist version of perdurantism. Such a view claims that an object that exists at the present time doesn't exist at that time in its entirety but exists there by having a present temporal part. Its other temporal parts, following perdurantism, exist at other times but, here comes the presentist's claim, those other times don't exist. But why claim that objects have temporal parts at other times than the present if these parts don't exist? According to Berit Brogaard (Brogaard 2000), this is the best way for perdurantism to avoid what is, according to her, the main charge against it in its non-presentist form: that it entails a changeless world. Indeed, it is considered by many as a serious objection to the non-presentist version of perdurantism (four-dimensionalism) that it entails the denial of change in the world. The objection goes as follows. 
Let us consider my neighbour Cyrano. At some past time $t_{1}$ he has a big nose. Suppose, then, that he undergoes a plastic surgery operation and so has, at a later time $t_{2}$, a small nose. What this amounts to, according to the fourdimensionalist, is that one of Cyrano's temporal parts has a big nose, and another has a small one. Thus, four-dimensionalists often take change to be very much like spatial variation since change is accounted for as the having of different properties by different parts. But when considering this account of change, some object to it $^{3}$ by claiming that what we want to give an account of is how a single object, a single individual like my neighbour Cyrano, can change, and the four-dimensionalist is telling us a story about different objects (different temporal parts) having different properties, and this is not the story we wanted to be told. What we have is not change of an individual, but replacement of one changeless object (one temporal part) by another changeless one. Instead of saying that Cyrano changed from $t_{1}$ to $t_{2}$ from having a big nose to having a small one, the four-dimensionalist says that the $t_{1}$-part of Cyrano has changelessly the property of having a big nose and the $t_{2}$-part of Cyrano has changelessly the property of having a small one. Since Cyrano himself is unable to lose or gain any such properties, this is why there is no room for genuine change in the four-dimensionalist's world. So, no concrete particular can ever genuinely change.

Brogaard claims that the presentist variant of perdurantism is capable of avoiding this objection: the $t_{1}$-part of Cyrano comes out of existence, by the passage of time, while the $t_{2}$-part comes into existence, and is then, in turn, replaced by another temporal part, and so on - thus the four-dimensionalist view that "[a perduring object like Cyrano] has temporal parts with different properties, just as a multicoloured strip of paper has spatial parts with different properties, and neither case involves change in the sense in which this word is commonly understood" (Brogaard 2000, p. 342) is avoided because there is no such 'strip'. And since only one temporal part of Cyrano exists, namely the present one, the only properties instantiated are the properties instantiated by it now - there is no having tenselessly any property and there is genuine change in the world, for, as she puts it "[...] the coming into existence of a new stage [i.e. temporal part] with a different non-relational property is a real change - and this in a way that captures our most basic intuitions according to which a change has taken place if the object stage that presently exists has different properties from those that existed previously" (Brogaard 2000, p. 348).

3 For statements of this objection see, for instance, Brogaard (2000), Haslanger (2003), Sider (2001), and Simons (2000). The origins of the objection seem to be found in McTaggart (1927). 
I do not see the force of this answer to the objection. Suppose that the 'no-change objection' succeeds against four-dimensionalism. The core idea of the objection is that instead of having a case where an object genuinely changes in its intrinsic properties, we have a case where one object (one temporal part) is replaced by another. Peter Simons, for instance, makes this claim when he says that the "four-dimensional alternative is not an explanation of change but an elimination of it, since nothing survives the change which has the contrary properties" (Simons 2000, p. 65). Now, if this objection applies to four-dimensionalism, it obviously applies to presentist perdurantism as well - what we have, in the situation as described by Brogaard, is not one and the same object that would change any of its intrinsic properties, but a series of numerically distinct objects coming into and going out of existence, when one of them is continuously replaced by another. The objection, then, applies here with as much force as before.

But perhaps the presentist perdurantist could claim that her view, but not the four-dimensionalist's, can accommodate the claim that there is change in what exists - and this is perhaps why Brogaard thinks that it can answer the no-change objection. Indeed, the four-dimensionalist's ontology is a static one since all times, past, present and future, equally exist, while the presentist component of presentist perdurantism allows for a world where what exists changes, since only the present time is real. But let us be careful about what such a claim is about: what we have here is that there is a difference in what exists, since the reality's stock contains, for example, Cyrano with a big nose at some time, and does not contain such an entity at a later time. But how does such a claim answer the no-change objection? It doesn't. It is true that the total reality's stock is different from time to time - but such a claim turns out to be true even under four-dimensionalism, since the reality's stock at some time is different from the reality's stock at some other time. The only difference is that under presentist perdurantism the reality's stock at a time is the reality's stock simpliciter, but this could hardly provide an answer to the no-change objection - granted, the defender of such a view could claim that "reality's stock simpliciter changes" but what else could such a claim mean, except, as we have seen, that the reality's stock is different from one time to another? - which, again, is true even under four-dimensionalism. Furthermore, and most importantly, even if there were a difference between the two views with respect to a 'change' in what exists (the reality's stock simpliciter), there certainly is no relevant difference in the account the two views provide of what we wanted to account for in the first place: intrinsic change of an entity such as Cyrano. Exactly as under four-dimensionalism, nothing (that is, no one thing) 
undergoes intrinsic change under presentist perdurantism - what we have in both cases, to repeat the objector's charge, is not change of an individual, but replacement of one changeless object (one temporal part) by another changeless one. And the same goes, of course, for the world as a whole (the reality's stock at a time) - the world is simply replaced by another, with the passage of time. It seems to me then that if the no-change objection succeeds against four-dimensionalism, it succeeds against presentist perdurantism as well. The diagnostic here is then that what causes trouble, according to the objector, if one wants a good account of change, is not the 'eternalist half' of four-dimensionalism, but rather its 'other half': perdurantism. And so, it is not presentism (the rejection of eternalism) that can save the case of four-dimensionalism. To yield a satisfactory and intuitive account of change, the objector would probably argue, the cure is not presentism, but endurantism (that is, the rejection of perdurantism).

$\$ 3$ Let us turn now to an independent difficulty with the presentist perdurantist view that four-dimensionalism does not encounter. Remember: presentist perdurantism claims that at the present time $t_{1}$ an object such as Cyrano doesn't exist in its entirety but exists there by having a $t_{1}$-part. The perdurantist component of this view would push us to say that he also has the rest of his temporal parts existing at other times, but according to presentism, those other times don't exist. But how is it possible to claim that material objects have temporal parts at other times than the present if these parts don't exist? Of course, following presentism, one could say that they existed and exist no longer, but in what sense would they be parts of the object? The very plausible principle involved here was put forward by Trenton Merricks: "an object cannot have another object as a part if that other object does not exist" (Merricks 1995, p. 524).

According to Sally Haslanger, this is in no way problematic to the holder of presentist perdurantism (see Haslanger 2003, p. 11): her grandmother, says she, is part of her family even though she does not presently exist, so if her family can have a non-existent part, why couldn't Cyrano? But such a line of 'argument by analogy' does not seem to be of great support, since typically a family and a material object like Cyrano or a table are conceived as different kinds of entities; thus, they are not analogous cases, and so any argument based on an alleged analogy is misguided. In order to make this argument by analogy sound and persuasive, it would be necessary first to show that a family is best conceived of as a material object like a table, but Haslanger does not do that - and the burden of proof $i s$ on her, since one could very well plausibly argue that a deceased member of a family is not a part of it: a family is probably best 
conceived of as a plurality, like a football team, and exactly as a football team can lose one of its members when this member ceases to exist, a family can lose a member in the same way, and in both cases the lost member is not a part of the team or the family anymore. So Haslanger's example doesn't prima facie seem to be a good one since the relation that family members or football team members bear to families and teams is a different relation than the parthood relation, and so this example cannot establish here that any non-existent object could be a part of anything existent, in the strong sense of "part" required by perdurantism - a doctrine according to which ordinary objects like tables are made up of temporal parts.

Concerns about family members set aside, the main ontological difficulty here is that it really seems very hard to admit that the objects (temporal parts) that compose another object (the whole Cyrano) exist only one after another, and so fail to ever make up the whole, as they should. Cyrano is supposed to be an aggregate of his temporal parts, but there never is a time (or time-span) at which such an aggregate exists.

Lawrence Brian Lombard thinks otherwise (see Lombard 1999). As he points out, rightly, one must carefully distinguish between two senses of "exist" if one is a perdurantist (both presentist and eternalist). First, the straightforward sense in which instantaneous temporal parts (let us admit here that there are such things, even if the perdurantist is not committed to them) exist at a certain time - if such entities exist at a certain time, they exist at this time entirely (they are three-dimensional entities) and they have all of their (spatial) parts at this time. Second, the derivative sense in which Cyrano, a whole composed of all of his temporal parts, exists at some time $\mathrm{t}-$ in this sense Cyrano exists at $t$ in virtue of having a temporal part that does; but one is enough, he does not need to have all of his parts at $t$. Of course, it is the second, derivative, sense that is the interesting one for the perdurantist here, the first one being accepted by everyone: if there are any three-dimensional instantaneous entities, it is uncontroversial that they exist entirely at the time they do.

Criticising Merricks's claim that an object cannot have another object as a part if that other object does not exist, Lombard says that "what is obvious is only that an object that exists at a time $t$, cannot have, at $t$, another object as a part, if that other part does not exist at $t$. But what the perdurantist wishes to say is not inconsistent with that. [...] What exists now in [the derivative] sense - [Cyrano] - is something that does (at some time or other) have parts that do not exist now; but what exists now in that sense does not now have those parts." (Lombard 1999, p. 256). 
But let us consider a true statement like "Cyrano has a present temporal part, but he is not identical to it". The problem here is simple: what is the referent of "Cyrano" and "he" in this statement? That is, what is this allegedly existent object that we are making reference to by these words? Does this object exist? Of course, it doesn't - only a part of it does. Perhaps the presentist perdurantist would say that the other parts existed and will exist and that there is a sense in which we can speak about Cyrano composed of all of its parts - but such a strategy does not seem to be available here, since it would mean that one is taking seriously something like an extra-temporal standpoint from which one refers to an entity composed of different temporal parts existing at different times. The eternalist could do that, of course, but not the presentist, since doing this would be like considering the different times as equally real. It seems that the only thing the presentist can do is to see things from a standpoint of some determinate moment of time (the present) and from this point of view nothing that could be the referent of "Cyrano" is available. So, in what sense can the referent of "Cyrano" be said to exist? In reply, Lombard would probably say that it exists derivatively - but what does this mean here? In the presentist's vocabulary, the "normal' meaning of "exists" is "exists now" - only what exists at the present time 'really' exists; remember that presentism is a doctrine about what there is in reality's stock, and that the doctrine claims that there is nothing more than the presently existing things. But now, the presentist perdurantist is telling us that there is more - that there is another, derivative, notion of existence according to which things composed of non-present (nonexistent) things exist. But, first, this seems to be a strong departure from one of the central claims of presentism to introduce two concepts of existence - one that sticks to the presentist view and another that does not seem to; and second, those two senses of "exist" are really distinct and irreducible one to the other. Compare to the case of the four-dimensionalist: she also uses two senses of existence, the 'ordinary' one, and the derivative, but here, the derivative sense does not carry any new ontological commitments - it only tells us that something can exist at a certain time by having a temporal part here, but it does not involve anything more than there already is in the first, nonderivative, sense of existence - so here, the derivative sense of existence is only a device to accommodate ordinary language, but nothing more.

So, it seems that the notion of having non-existent parts seems to carry with it an ill-motivated plurality of notions of existence. But even if such notions of existence were to be accepted and endorsed, this would not leave the presentist perdurantist view cleaned of problems with the having of parts that don't exist. 
To see this, let us make a small detour and first consider another rescue mission that the defender of the presentist perdurantist view might want to undertake to answer the problem we had: that the temporal parts that compose an object exist only one after another, and so fail to ever make up the whole - and so it seems that Cyrano never really exists. Here is a remedy that is readily at hand: deny that Cyrano is a four-dimensional whole made up of temporal parts, and claim, rather, that he is an instantaneous temporal part which persists through time by having other temporal parts at other times as temporal counterparts. This amounts to a rejection of the more traditional perdurantist 'worm view' in favour of the so-called 'stage view' - since ordinary objects like Cyrano, according to this view, are the instantaneous stages rather than the worms made up of them. (This is the view defended by Sider (2001).) It is not my purpose to discuss the stage view here; I only wish to see how relevant it is to the combination of perdurantism and presentism. And it is obvious that it has the nice advantage to answer our objection: if Cyrano is an instantaneous stage rather than a temporally extended worm, then there is of course no problem about having non-existent parts, since nobody claims that he has any, and there is no problem about how successive stages could make up a whole, since nobody really cares about the wholes (Sider claims that the wholes exist in addition to stages, but that these are not the ordinary objects we usually care about and quantify over - so at least the pressure on the presentist perdurantist becomes here much weaker).

So isn't there a good reason for the presentist perdurantist to become a stage theorist? I think not. Consider the claim that Cyrano has now a small nose, but he had a big nose before. The stage view provides a counterparttheoretic analysis of such a claim: Cyrano has now a small nose, but he has a past counterpart that has (had) a big nose. Now, what is needed for Cyrano to have such a counterpart? Two stages are counterparts iff they are related by the counterpart relation. The counterpart relation is a relation of similarity, some sort of spatio-temporal contiguity and/or continuity, and causality. Actually, no stage theorist (including Sider) says what exactly the nature of the counterpart relation is, but my point here is simply that whatever the counterpart relation is, it just cannot hold between different stages if one is a stage view theorist who wants to be a presentist as well. Take Cyrano at $t_{1}$ with a big nose and Cyrano at $t_{2}$ (the present time) with a small nose. These two different individuals are supposed to be counterpart-related. But how could they ever be? How could a non-existent individual (Cyrano at $\mathrm{t}_{1}$ ) bear any degree of resemblance and have any other (spatio-temporal and causal) relations to an existent flesh-andblood individual (Cyrano at $\mathrm{t}_{2}$ - the present time)? Nothing non-existent is 
sufficiently similar and related to anything existent to be counterpart-related (if it makes sense at all to even speak about 'non-existent things'). And generally, the counterpart relation will never hold between the two individuals (the two numerically distinct Cyranos) simply because there never is a time when the two individuals both exist - and so there never is a time when both relata of the counterpart relation exist. How could then the counterpart relation ever succeed in doing the job it promises if the relata that it is supposed to relate never both exist? Of course, one could say here that two individuals are counterparts iff, if they were both present (that is, if they both existed), then they would be counterpart-related, but such a situation never is the case, and so the conditional here would always be vacuous ${ }^{4}$. In short then, the stage view does not really help the business of the presentist perdurantist because, even if it seems to answer the objection about parts that don't exist, it immediately yields a different but parallel objection about counterparts that don't exist.

And it is easy to see how this problem also makes trouble for the presentist perdurantist who wishes to maintain the worm view - exactly as different counterparts need to be related by a counterpart relation in order to be counterparts, different parts of four-dimensional worms need to be 'glued together' in some way in order to make up the wholes that are the individuals we are interested in, like Cyrano. Finding such a glue (that is, a unification relation that makes the successive temporal parts of a single four-dimensional worm ontologically stick together) is not an easy task even for the four-dimensionalist, but for the presentist perdurantist, the task just seems impossible to be carried out. For what would such a glue relation be? Again, it might involve resemblance, or causality, or spatio-temporal contiguity, or something else - in fact, whatever serves the stage theorist to load his counterpart relation can serve the worm theorist as the glue. And so, of course, the same problems as those we have just seen with the stage view will appear for the worm view: how could one existent thing and one non-existent thing be glued together (if, again, I may be allowed to even say such a weird sentence)? That is, what kind of ontological glue would be needed in order to authorise that mereological composition takes place between a thing that exists and nothing? Perhaps one could propose here, as a remedy, to follow the line of almost all four-dimensionalists who are friends of the principle of an entirely unrestricted mereological composition (for independent reasons, mainly to avoid problems with ontological vagueness) - so that the glue relation might not be restricted at all. But however unrestricted, it certainly cannot be that unrestricted - unrestricted mereological composition is restricted to existent things only, and any attempts to take

4 This parallels what Lewis (1986, p. 238) says about modal counterparts. 
away even this restriction would lead one to weird places where no sensible metaphysician (I hope) wants to go - like commitments to individuals made up of the top half of Cyrano's body today, and all of the tropical fish of the $19^{\text {th }}$ century, and three unicorns, and two fire-breathing dragons.

$\$ 4$ In the light of the above, I cannot see a real motivation for the presentist perdurantist view, especially since, as we have seen, its allegedly good treatment of the no-change objection turned out not to be very satisfactory in the end.

Jiri Benovksy

Department of Philosophy

University of Fribourg, Switzerland

jiri@benovsky.com

\section{References}

Brogaard, Berit (2000) 'Presentist Four-dimensionalism'. The Monist 83(3), pp. 341-354.

Haslanger, Sally (2003) 'Persistence Through Time'. In: Loux \& Zimmerman, 2003, pp. 315-54.

Lewis, David (1986) On the Plurality of Worlds. Oxford: Blackwell Publishers.

Lombard, Lawrence B. (1999) 'On the Alleged Incompatibility of Presentism and Temporal Parts'. Philosophia 27, pp. 253-260.

Loux, Michael J. \& Dean W. Zimmerman (eds.) (2003) The Oxford Handbook of Metaphysics. Oxford: Oxford University Press.

McTaggart, J. M. E. (1927) The Nature of Existence, volume 2. Cambridge, UK: Cambridge University Press.

Merricks, Trenton (1995) 'On the Incompatibility of Enduring and Perduring Entities'. Mind 104, pp. 523-531.

Sider, Theodore (2001) Four-dimensionalism. Oxford: Clarendon Press.

Simons, Peter (2000) 'Continuants and Occurrents'. The Aristotelian Society 74, pp. $78-101$.

Zimmerman, Dean W. (1998) 'Temporary Intrinsics and Presentism'. In: Peter Van Inwagen \& Dean W. Zimmerman (eds.) (1998): Metaphysics: The Big Questions. Oxford: Blackwell Publishers. 